\title{
Sexual dysfunction: prevalence and associated factors in patients with mental illness receiving psychotropic medication in Nigeria
}

\author{
Samuel Obateru Osasona, Mary Ehimigbai
}

Department of Mental Health, University of Benin Teaching Hospital, Benin City.

\author{
Email: \\ maryee2000@gmail.com
}

\begin{abstract}
Objectives: The objectives were to determine the prevalence of total and specific sexual dysfunction among psychiatric out-patients taking psychotropic medication, assess its relationship with some demographic and clinical variables, determine the effect of sexual dysfunction on subject's self- esteem and compliance with medication.

Methods: This descriptive, cross-sectional study was conducted in the psychiatric out-patient clinic of a Tertiary Care Teaching Hospital in Benin City. The International Index of Erectile Functioning (IIEF), Rosenberg's self esteem scale and a socio-demographic and clinical data questionnaire were administered to 300 participants; 150 (50\%) psychiatric male patients and 150 $(50 \%)$ controls.

Results: The prevalence of total sexual dysfunction was 48.7\%, while that of the specific SDs ranged from $20.0 \%$ to $39.3 \%$, with erectile dysfunction having the highest proportion. Age, marital status, class, dose of psychotropic medication, poly-pharmacy and duration of treatment were significantly associated with SD. Majority of patient with SD reported poor compliance with medication. Self-esteem scores had significant inverse relationship with total SD scores.

Conclusion: Sexual dysfunction is prevalent amongst psychiatric patients taking psychiatric medication and has negative implications for self-esteem and medication compliance. Routine enquiry about sexual symptoms by physicians and prompt treatment of SD might enhance overall treatment success.
\end{abstract}

Keywords: Sexual dysfunction, psychiatric patients, psychotropic medication, Nigeria.

DOI: https://dx.doi.org/10.4314/ahs.v19i4.18

Cite as: Osasona SO, Ehimigbai M. Sexual dysfunction: prevalence and associated factors in patients with mental illness receiving $p$ sychotropic medication in Nigeria. Afri Health Sci.2019;19(4):2973-2984. https://dx.doi.org/10.4314/abs.v19i4.18

\section{Introduction}

Normal sexual functioning is one of the most important components of quality of life and maintenance of satisfying intimate relationship. ${ }^{1}$ Adequate sexual expression is essential to human relationships and provides a sense of wellbeing which potentially contributes to improved subjective health and overall quality of life. ${ }^{2}$ Poor self-esteem and lack of compliance with medication can be consequent upon perceived loss of normal sexual function-

\section{Corresponding author: \\ Samuel Obateru Osasona, Department of Mental Health, University of Benin Teaching Hospital, Benin City, Edo State, Nigeria \\ Telephone number: +2348032561215 \\ Email: samuelosasona@gmail.com}

ing. According to (ICD-10) ${ }^{3}$ the term sexual dysfunction (SD) describes the inability of an individual to participate in a sexual relationship as he or she would wish and includes lack of interest, lack of enjoyment, failure of physiological responses and/or problems with erection. ${ }^{4}$ Sexual dysfunction (SD) is common in the general population and studies conducted across different geographical regions reveal high prevalence rates. ${ }^{5,6,7}$ However SD is more prevalent among mentally ill patients and patients taking psychotropic medications than among healthy controls. ${ }^{8,9,10,11,12}$

The high prevalence of SD among psychiatric patients may be related, mostly to two factors. First, SD may be related to the psychopathology of the psychiatric disorder which may impact negatively on patients' sexual functioning. Epidemiological and clinical studies show that schizophrenia and depression are associated with impairment of sexual function and satisfaction even in untreatLicense (https://creativecommons.org/licenses/BY/4.0), which permits unrestricted use, distribution, and reproduction in any medium, provided the original work is properly cited. 
ed patients; ${ }^{8}$ both positive symptoms (e.g hallucination) and negative symptoms of schizophrenia may affect the patients interpersonal relationship and impact negatively on their sexual functioning ${ }^{8,10}$ Aizenberg and his colleagues ${ }^{10}$ reported that majority of untreated schizophrenia patients had a reduced desired for sex compared with healthy control group, similarly mood disorders interfere with libido and erectile function ${ }^{8}$

Secondly, SD may be related to treatment with psychotropic medications especially antipsychotics and antidepressant and SD caused by psychotropic medication has become an increasingly important topic. ${ }^{13}$ Serretti and Chiesa ${ }^{14}$ reported that both typical and some atypical antipsychotics are frequently associated with SD. Kockotta and Pfeiffer ${ }^{15}$ reported that SD was worse in schizophrenic patients taking antipsychotic medication compared with un-medicated patients. Selective serotonin re-uptake inhibitors (SSRI) may delay ejaculation and female orgasm and cause decreased libido and erectile impairment ${ }^{16}$. Thus many patients experience SD as a side effect of psychotropic medications. Although the exact mechanism of psychotropic related SD is poorly understood $^{17}$, the pharmacological profile of individual drugs may play important roles.

Despite the reported high prevalence of SD among psychiatric patients, most sufferers do not seek help as it is often not reported to doctors.18 Factors reported to be responsible for this include feeling of embarrassment, shame, fear of stigmatization and threat to marriage ${ }^{1,18}$, Similarly many physicians are reluctant to engage with their patients on issues bothering on sexual functioning. Clayton and his colleagues ${ }^{19}$ cited socio-cultural barriers, inadequate training and knowledge about sexual functioning and treatment of dysfunction, and fear of being misconstrued as the reasons.

The effects of sexual side effects of psychotropic medication on patients' self- esteem and compliance with treatment has long been known. ${ }^{20}$ Untreated SD may portend serious implication for the psychiatric patients as it further lowers their quality of life and self- esteem, and impact negatively on compliance with medication.Studies have shown that sexual functioning is positively correlated with self-esteem and decreased sexual satisfaction negatively impact self-esteem causing loss of confidence. ${ }^{20,21}$ The negative consequences that untreated SD portends for patients wellbeing/quality of life, self- esteem and overall management success underscores the importance of epidemiological studies aimed at identifying sufferers and treating them accordingly.

Although many researchers in the western countries have surveyed SD among psychiatric patients and have made significant contributions to knowledge, awareness and data base, there is, as yet, inadequate research in Nigeria and sub- Sahara Africa. The few available studies mostly adopted restrictive methods by examining patients with a specific dysfunction (e.g erectile dysfunction) alone; ${ }^{22-24}$ patients with a specific psychiatric diagnosis (e.g psychotic disorders or schizophrenia) alone;11 or patients on conventional antipsychotic medicationsalone,11,14 and none, to the best of our literature search, has examined the relationship between SD and patients' self-esteem and compliance to psychotropic medications. This study was conducted on a broader scale. Thus the aims of this study were to: 1) determine the prevalence of total and specific SD in male psychiatric patients and compare these with the control group, 2) assess the association between SD and some demographic and clinical variables,3) determine the relationship between SD and patients' self- esteem, and 4) determine the relationship between SD and compliance with psychotropic medication. It is believed that this study will make modest contributions to knowledge about SD among psychiatric patients and bridge the gap in data base especially in Nigeria and Africa.

\section{Materials and methods \\ Study design}

This study was conducted at the psychiatric out-patient clinic of a teaching hospital in Benin, Nigeria. The hospital is a foremost tertiary institution in the city and the entire Edo State. It receives referrals from private, primary and secondary health care facilities from within and outside the geopolitical zone. The out-patient clinics are run three times a week for follow up consultations for patients that are mostly mentally stable. Information from the medical records department of the hospital showed that about 20 patients with a variety of psychiatric diagnoses attended the out-patient clinic every clinic day. A cross sectional and descriptive design was employed and the study was conducted between May, 2017 and April, 2018.

\section{Sampling:}

The sample size required for the study was calculated 
using the formula for descriptive cross-sectional study. ${ }^{25}$ Prevalence value of $16 \%$ reported among male psychiatric patients in a previous study in Nigeria9 was used and a confidence interval of $95 \%$ was assumed. The calculated minimum size was 206 . However, $50 \%$ of the value (103) was added in anticipation of possible rejection of questionnaires that would be badly filled. Thus 309 questionnaires were administered to consecutive attendees at the out-patient clinic and their relatives (who served as control).

\section{Measures}

The International Index of Erectile Functioning (IIEF), the Rosenberg's self- esteem scale and a socio-demographic and clinical data questionnaire were used to assess the participants.

The International Index of Erectile Function Questionnaire (IIEF) ${ }^{26}$ : This is a self-report questionnaire for assessing male sexual functions. It was developed by an International Panel of experts through an extensive review of the literature and existing questionnaires in addition to detailed interview of men with sexual dysfunction and their partners. ${ }^{22,26}$ The instrument consists of 15 questions which are divided into five domains; each domain addresses a unique dimension of sexual function: Erectile Function (Q1-5, 15), (Orgasmic Function (Q9,10), Sexual Desire (Q11, 12), Intercourse Satisfaction (Q6-8), and overall satisfaction (Q13,14), Q1-10 are rated on a 6-point Likert-type scale (0-5) with 0 indicating no sexual activity or no attempt; while Q11-15 are rated on a 5 -point scale (1-5). Domain scores are computed by summing the scores for individual items in each domain. Total IIEF questionnaire scores range from $0-75$, with higher scores indicating better sexual functioning. Responses to each question are based on a man's experience over the past 4 weeks. The IIEF has been used by previous authors in Nigeria 6,9,24 and a reliabilityoefficient (Cronbach's alpha) of 0.921 was obtained ${ }^{24}$

The instrument has a scoring algorithm showing the five domains of male sexual dysfunction with their different cut off scores[for example, in the erectile function domain, the cut off scores for the degrees of erectile dysfunction are: 1-10 (severe); 11-16 (moderate); 17-21 (mild to moderate); ${ }^{22-25}$ (mild); ${ }^{26-30}$ (no dysfunction). For the purpose of this study and for ease of statistical analysis, all degrees of dysfunction (mild to severe) were considered as 'dysfunction'. Thus, a binary variable "dysfunction/No dysfunction emerged. The same method was adopted for all the domains using their respective scoring algorithm. The scoring algorithm has been used by previous authors in Nigeria. 11,27Our primary outcome measure is the rate of total SD (all patients with at least one type SD) while the secondary outcome measure is the rate of specific (domain) SD.

The Rosenberg's Self-esteem Scale ${ }^{29}$ : This is a 10-item self-report likert-type measure that assesses an individual's overall sense of self- worth or self- acceptance. Response options of the scale range from 'strongly disagree' to 'strongly agree'. The sum of the ratings assigned to all the items, after a reverse scoring of the positively worded items gives the global scores which range from 10 to 40 with higher scores indicating higher self- esteem. Patients were rated as having low self-esteem if they scored below the mean score on the self- esteem scale.

Rosenberg initially found it to have strong internal consistency reliability of $0.93 .^{29}$ In Nigeria, Okwaraji and his colleagues $^{30}$ established a Cronbach alpha of 0.84 and two week test-retest reliability coefficient of 0.76 .

A structured questionnaire was designed by the authors to elicit information on subjects' socio- demographic and some clinical variables. Information on patients' compliance with medication was based on patients' self- report and was rated as good or poor.

\section{Ethical considerations}

The study protocol was approved by the research and ethics committee of the University of Benin Teaching Hospital. All participants were informed that the study was confidential and that participation was voluntary. Verbal informed consent was obtained from them.

Participants: Consecutive male attendees at the psychiatric out-patient clinic diagnosed with various psychiatric disorders based on ICD-10 criteria and stabilized on a variety of psychotropic medications were recruited into the study.

\section{Eligibility criteria included}

Being diagnosed with a particular psychiatric disorder based on ICD-10 diagnostic criteria,

Regular use of, at least, a psychotropic medication in the last 6 months, 
Aged between 18 and 60 years,

Willingness to voluntarily participate in the study and ability to give informed consent.

Exclusion criteria included

Having a chronic illness such as uncontrolled hypertension, diabetes mellitus or other

endocrine

disorders, cardiovascular disorders e.g. recent myocardia infarction

Receiving any therapy, using any medication or substances that are known to interfere with erectile function.

\section{Procedure:}

The self-report questionnaires were administered to consecutive male clinic attendees who met the inclusion criteria after a clinical assessment of the patients by the authors (who are consultant Psychiatrists) in order to ensure their physical and mental fitness for the study. The patients' case files were also reviewed in order to corroborate and supplement patients' self-reported information and retrieve relevant clinical details. The questionnaires were also administered to consecutive male relatives/care givers who accompanied the patients to the hospital and met the inclusion criteria. They acted as control group. Retrieved questionnaires were checked for correctness and coded.

\section{Statistical analysis:}

Data were analyzed using version 16 of the Statistical Package for Social Sciences (SPSS) and descriptive statistics (frequencies and percentages) were computed for the variables. Categorical variables were compared using the chi square test, while the mean age of patient and control group, were compared using independent sample t-test. The Pearson's correlation analysis was used to assess relationship between some continuous variables, while logistic regression was employed to determine the risk factors for sexual dysfunction. The statistical level of significance was set at the $5 \%$ level $(\mathrm{P}<0.05)$.

\section{Results}

\section{Demographic characteristics of the subjects}

A total of 309 questionnaires were administered and retrieved, nine were rejected because they were badly filled, thus data from 300 participants $150(50 \%)$ psychiatric patients and $150(50 \%)$ controls) were analyzed. The mean age of the patients was $38.43+13.52$ years while that of the control group was 39.87 $\neg+13.29$. There was no statistically significant difference between the mean ages of the patients and control group $(\mathrm{t}=-0.926, \mathrm{p}=0.355,95 \%$ $\mathrm{CI}=-4.479-1.613)$. Cross tabulation with Chi2 test also revealed that patients and controls did not differ significantly on any of their socio-demographic variables (age, marital status, sexual partner and so forth).

\section{Clinical characteristics}

Frequency distribution showed that the highest proportion of the patients $(45.39 \%)$ had psychotic disorders, while the least proportion $(7.3 \%)$ had somatoform disorders. More than one-third (38.7\%) of the patients were being treated with two or more psychotropic drugs (poly-pharmacy) while those on mood stabilizer alone constituted the least proportion $(6.7 \%)$. The average duration of illness and treatment were $7.41+5.75$ and $6.15+5.22$ years respectively while the mean daily dose of antipsychotic medications (chlorpromazine equivalent) was 297 $+165 \mathrm{mg} /$ day. Among patients who reported SD, vast majority $(78.9 \%)$ never discussed the problem with their doctors.

More than one-third (37.3\%) of the patients reported poor compliance with their medications, and among them, $32(57.1 \%)$ gave sexual side effects as the reason for the poor compliance. The vast majority of the patients $(81.3 \%)$ reported that their premorbid sexual functioning was satisfactory.

The rate of SD on the different domains were: Erectile dysfunction, $39.3 \%$; orgasmic dysfunction, $20.0 \%$; sexual desire dysfunction, $23.3 \%$; intercourse dissatisfaction, $26.7 \%$ and overall dissatisfaction, $28.7 \%$. Almost half $(48.7 \%)$ of the patients had at least one type of SD (total SD) (Table 1). 
Table 1: Frequency distribution of the clinical variables of the patients

\begin{tabular}{|c|c|c|}
\hline Variables & $\begin{array}{c}\text { Freq } \\
\text { n }\end{array}$ & Percent \\
\hline \multicolumn{3}{|l|}{ Category of Psychiatric Diagnosis } \\
\hline Anxiety disorders & 13 & 8.7 \\
\hline Mood disorders & 58 & 38.7 \\
\hline Psychotic disorders & 68 & 45.3 \\
\hline Somatoform disorders & 11 & 7.3 \\
\hline \multicolumn{3}{|l|}{ Class of Psychotropic Medication } \\
\hline Atypical antipsychotic alone & 24 & 16.0 \\
\hline Typical antipsychotic alone & 20 & 13.3 \\
\hline SSRI alone & 24 & 16.0 \\
\hline Tricyclic antidepressant alone & 14 & 9.3 \\
\hline Mood stabilizer alone & 10 & 6.7 \\
\hline Combination (poly-pharmacy) & 58 & 38.7 \\
\hline \multicolumn{3}{|c|}{ Dose of antipsychotic $(\mathrm{mg} / \mathrm{day})(\mathrm{n}=97) *$} \\
\hline$<300$ & 50 & 33.3 \\
\hline $300-500$ & 36 & 24.0 \\
\hline$>500$ & 11 & 7.3 \\
\hline \multicolumn{3}{|l|}{ Duration of Illness (years) } \\
\hline$<5$ & 76 & 50.7 \\
\hline $5-10$ & 42 & 28.0 \\
\hline$>10$ & 32 & 21.3 \\
\hline \multicolumn{3}{|l|}{ Duration of Treatment (years) } \\
\hline$<5$ & 87 & 58.0 \\
\hline $5-10$ & 38 & 25.3 \\
\hline$>10$ & 25 & 16.7 \\
\hline \multicolumn{3}{|c|}{ Ever Discussed SD with the Doctor? $(\mathbf{n}=76) * *$} \\
\hline Yes & 16 & 21.1 \\
\hline No & 60 & 78.9 \\
\hline \multicolumn{3}{|c|}{ Medication Compliance (Self- report) } \\
\hline Good & 94 & 62.7 \\
\hline Poor & 56 & 37.3 \\
\hline \multicolumn{3}{|l|}{ Reason For Poor Compliance $(n=56)$} \\
\hline Sexual side effect & 32 & 57.1 \\
\hline Other reasons & 24 & 42.9 \\
\hline \multicolumn{3}{|l|}{ Premorbid Sexual Functioning } \\
\hline Satisfactory & 122 & 81.3 \\
\hline Unsatisfactory & 28 & 18.7 \\
\hline
\end{tabular}


Table 1: Frequency distribution of the clinical variables of the patients contd.

\begin{tabular}{|c|c|c|}
\hline Variables & $\begin{array}{l}\text { Frequency }(\mathrm{N}=150) \\
\mathrm{n}\end{array}$ & Percent \\
\hline \multicolumn{3}{|c|}{ Total Sexual dysfunction*** } \\
\hline No dysfunction & 77 & 51.3 \\
\hline Dysfunction & 73 & 48.7 \\
\hline \multicolumn{3}{|l|}{ Erectile dysfunction } \\
\hline No dysfunction & 91 & 60.7 \\
\hline Dysfunction & 59 & 39.3 \\
\hline \multicolumn{3}{|c|}{ Orgasmic dysfunction } \\
\hline No dysfunction & 120 & 80.0 \\
\hline Dysfunction & 30 & 20.0 \\
\hline \multicolumn{3}{|c|}{ Sexual Desire dysfunction } \\
\hline No dysfunction & 115 & 76.7 \\
\hline Dysfunction & 35 & 23.3 \\
\hline \multicolumn{3}{|c|}{ Intercourse Satisfaction dysfunction } \\
\hline No dysfunction & 110 & 73.3 \\
\hline Dysfunction & 40 & 26.7 \\
\hline \multicolumn{3}{|c|}{ Overall Satisfaction dysfunction } \\
\hline No dysfunction & 107 & 71.3 \\
\hline Dysfunction & 43 & 28.7 \\
\hline
\end{tabular}

Comparison of the rates of SD on all the domains using higher rates of SD on all domains than the control group the Chi2 test showed that the patients had significantly (Table 2).

Table 2: Comparison of the rates of SD (total and specific) between patient and control groups

\begin{tabular}{|c|c|c|c|c|c|c|}
\hline \multirow[b]{2}{*}{ Variables } & \multicolumn{2}{|l|}{ GROUP } & \multirow[b]{2}{*}{$\chi^{2}$} & \multirow[b]{2}{*}{$\mathrm{df}$} & & \multirow[b]{2}{*}{ p-value } \\
\hline & $\begin{array}{l}\text { Patient } \\
\mathrm{n}=150(\%)\end{array}$ & $\begin{array}{l}\text { Control } \\
\mathrm{n}=150(\%)\end{array}$ & & & & \\
\hline \multicolumn{7}{|l|}{ Total Dysfunction* } \\
\hline No dysfunction & $77(51.3)$ & $39(26.0)$ & 16.470 & 1 & & $<0.001$ \\
\hline Dysfunction & $73(48.7)$ & $111(74.0)$ & & & & \\
\hline \multicolumn{7}{|c|}{ Erectile Dysfunction } \\
\hline No dysfunction & $91(60.7)$ & $125(83.3)$ & 19.114 & & 1 & $<0.001$ \\
\hline Dysfunction & $59(39.3)$ & $25(16.7)$ & & & & \\
\hline \multicolumn{7}{|c|}{ Orgasmic Dysfunction } \\
\hline No dysfunction & $120(80.0)$ & $136(90.7)$ & 6.818 & & 1 & 0.009 \\
\hline Dysfunction & $30(20.0)$ & $14(9.3)$ & & & & \\
\hline Sexual & & & & & & \\
\hline \multicolumn{7}{|l|}{ Dysfunction } \\
\hline No dysfunction & $115(76.7)$ & $137(91.3)$ & 12.004 & & 1 & 0.001 \\
\hline Dysfunction & $35(23.3)$ & $13(8.7)$ & & & & \\
\hline \multicolumn{7}{|c|}{ Intercourse Dissatisfaction } \\
\hline No dysfunction & $110(73.3)$ & $131(87.3)$ & 9.304 & & 1 & 0.002 \\
\hline Dysfunction & $40(26.7)$ & $19(12.7)$ & & & & \\
\hline \multicolumn{7}{|l|}{ Overall } \\
\hline \multicolumn{7}{|l|}{ Dissatisfaction } \\
\hline No dysfunction & $107(71.3)$ & $129(86.0)$ & 9.613 & & 1 & 0.002 \\
\hline Dysfunction & $43(28.7)$ & $21(14.0)$ & & & & \\
\hline
\end{tabular}




\section{Correlates of sexual dysfunction}

$\mathrm{Chi}^{2}$ test revealed that Erectile dysfunction is significantly associated with age $(\mathrm{P}=0.037)$, class of psychotropic medication $(\mathrm{P}=0.001)$, poly-pharmacy $(\mathrm{P}=0.000)$, dose of antipsychotics (0.000), duration of illness $(\mathrm{P}=0.000)$, duration of treatment $(\mathrm{P}=0.000)$. Orgasmic dysfunction had significant association with marital status $(\mathrm{P}=0.033)$. Sexual desire dysfunction was significantly associated with age $(\mathrm{P}=0.013)$, duration of illness and treatment $(\mathrm{P}=0.009$ and 0.044 respectively). Intercourse dissatis- faction had significant association with marital status $(\mathrm{P}=0.032)$ and poly-pharmacy $(\mathrm{P}=0.047)$.

There was significant association between overall dissatisfaction; and marital status $(\mathrm{P}=0.020)$, poly-pharmacy $(\mathrm{P}=0.009)$, dose of antipsychotics $(\mathrm{p}=0.000)$, duration of illness and treatment $(\mathrm{P}=0.007$ and 0.007 respectively). Medication compliance was significantly associated with all the domains of sexual dysfunction while self-esteem had significant association with erectile dysfunction $(\mathrm{P}=$ 0.001), and overall dissatisfaction $(\mathrm{P}=0.026)$ (Table 3).

Table 3: Summary of association between specific sexual dysfunctions and some demographic/clinical variables

\begin{tabular}{|c|c|c|c|c|c|}
\hline \multirow[t]{2}{*}{$\begin{array}{l}\text { Demographic and } \\
\text { Clinical variables }\end{array}$} & $\begin{array}{l}\text { Spec } \\
\text { ific Sexual Dysfunction } \\
\text { Erectile }\end{array}$ & Orgasmic & Desire & $\begin{array}{l}\text { Intercourse } \\
\text { Satisfaction }\end{array}$ & \multirow{2}{*}{$\begin{array}{l}\text { Overall } \\
\text { Satisfaction } \\
\mathrm{X}^{2} \quad P\end{array}$} \\
\hline & $\mathbf{X}^{2} \quad P$ & $\mathrm{X}^{2} \quad P$ & $\mathbf{X}^{2}$ & $\mathrm{X}^{2} \quad P$ & \\
\hline 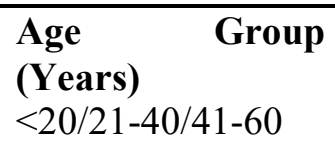 & $6.606,0.037$ & $.076, .963$ & $8.742, .031$ & $.045, .979$ & $5.844, .054$ \\
\hline $\begin{array}{l}\text { Marital Status } \\
\text { Single/Currently } \\
\text { married/Previously } \\
\text { married }\end{array}$ & $4.219,0.121$ & $6.830, .033$ & $3.132, .209$ & $6.873, .032$ & $7.861, .020$ \\
\hline $\begin{array}{l}\text { Category of } \\
\text { Psychiatric } \\
\text { Disorders } \\
\text { *Anxiety/Mood/Ps } \\
\text { ychotic/Somatofor } \\
\mathrm{m}\end{array}$ & $6.017, .198$ & $2.341, .673$ & $2.656, .617$ & $4.401, .354$ & $3.406, .492$ \\
\hline $\begin{array}{l}\text { Class of } \\
\text { psychotropic } \\
\text { medications } \\
\text { **Atypical/Typical } \\
\text { /SSRI/TCA/Mood } \\
\text { stabilizers }\end{array}$ & $20.063, .001$ & $3.479, .627$ & $6.985, .222$ & $8.723, .121$ & \\
\hline
\end{tabular}

Logistic regression analysis showed that only dose of psychotropic medication independently predicted SD. All the variables entered into the logistic model accounted for $29.1 \%$ to $39.0 \%$ of the variation in sexual dysfunction (Table 4). Erectile, orgasmic and intercourse satisfaction functions were the three domains with the strongest positive correlation with overall satisfaction. Erectile function scores had highly significant inverse relationship with age but highly significant positive correlation with self-esteem (Table 5). 
Table 4: Predictors of sexual dysfunction (logistic regression)

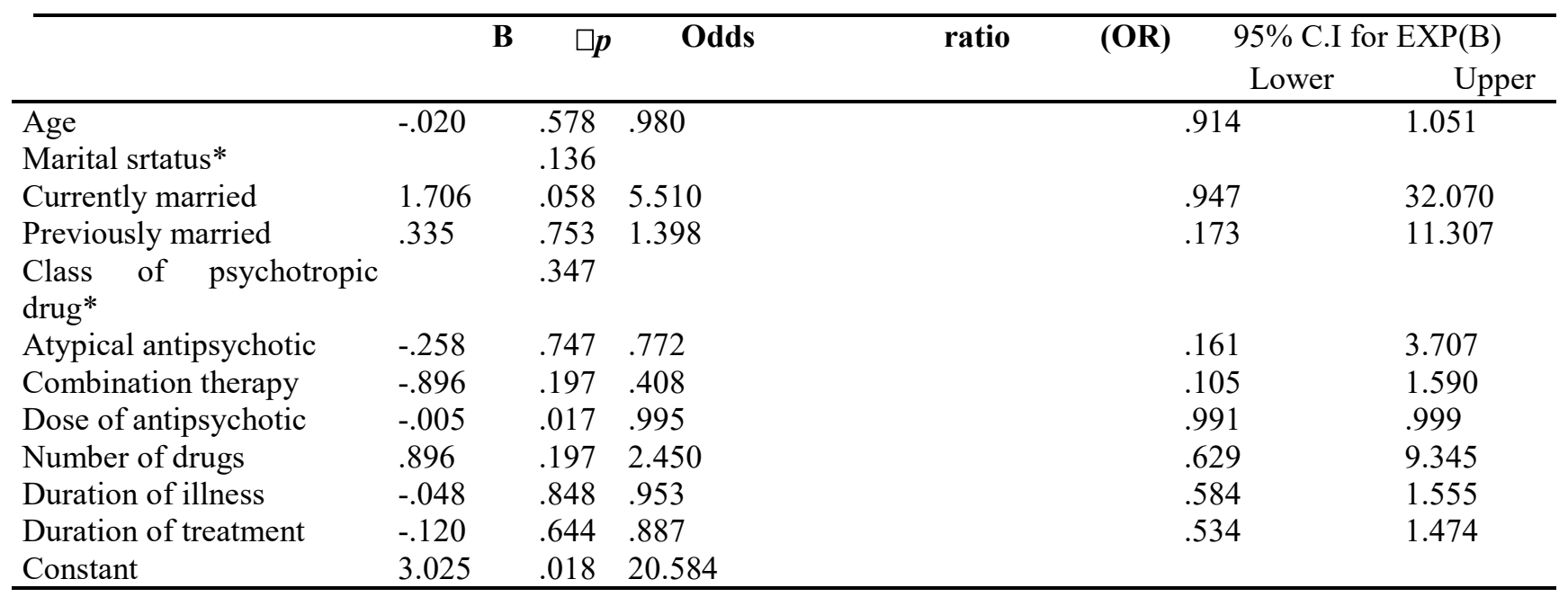

*Reference category; Being single, Typical antipsychotic, $\mathbf{R}^{2 \text { : Coefficient of determination of the logistic model. }}$

$R^{2}=\mathbf{2 9 . 1} \%$ to $39.0 \%$

Table 5: Correlations among domains of sexual functions, age and self esteem

\begin{tabular}{|c|c|c|c|c|c|c|c|}
\hline \multirow[t]{2}{*}{ Age(years) } & \multirow{2}{*}{$\begin{array}{l}\text { Pearson Correlation } \\
\text { Sig. (2-tailed) }\end{array}$} & $-.253^{* *}$ & .031 & $-.147^{*}$ & -.019 & -.107 & -.099 \\
\hline & & .000 & .587 & .011 & .745 & .065 & .088 \\
\hline \multirow[t]{2}{*}{ Erectile function scores } & \multirow{2}{*}{$\begin{array}{l}\text { Pearson Correlation } \\
\text { Sig. (2-tailed) }\end{array}$} & & $.350^{* *}$ & $.458^{* *}$ & $.445^{* *}$ & $.526^{* *}$ & $.386^{* *}$ \\
\hline & & & .000 & .000 & .000 & .000 & .000 \\
\hline \multirow[t]{2}{*}{ Orgasmic function scores } & \multirow{2}{*}{$\begin{array}{l}\text { Pearson Correlation } \\
\text { Sig. (2-tailed) }\end{array}$} & & & $.132^{*}$ & $.723^{* *}$ & $.603^{* *}$ & .100 \\
\hline & & & & .022 & .000 & .000 & .084 \\
\hline \multirow[t]{2}{*}{ Sexual desire scores } & \multirow{2}{*}{$\begin{array}{l}\text { Pearson Correlation } \\
\text { Sig. (2-tailed) }\end{array}$} & & & & $.337^{* *}$ & $.403^{* *}$ & $.293^{* *}$ \\
\hline & & & & & .000 & .000 & .000 \\
\hline \multirow[t]{2}{*}{ Intercourse satisfaction scores } & \multirow{2}{*}{$\begin{array}{l}\text { Pearson Correlation } \\
\text { Sig. (2-tailed) }\end{array}$} & & & & & $.682^{* *}$ & $.155^{* *}$ \\
\hline & & & & & & .000 & .007 \\
\hline \multirow[t]{2}{*}{ Overall satisfaction scores } & \multirow{2}{*}{$\begin{array}{l}\text { Pearson Correlation } \\
\text { Sig. (2-tailed) }\end{array}$} & & & & & & $.228^{* *}$ \\
\hline & & & & & & & .000 \\
\hline Self-esteem scores & $\begin{array}{l}\text { Pearson Correlation } \\
\text { Sig. (2-tailed) }\end{array}$ & & & & & & \\
\hline
\end{tabular}

\section{Discussion}

This study examined sexual dysfunction among patients attending a psychiatric out-patient clinic in Benin City,
Nigeria. The patients' mean age of 38.43 years is noteworthy; it is within the reproductive and sexually active age group. Thus sexual difficulties could be an important source of concern to the respondents. 


\section{Prevalence of sexual dysfunction}

The prevalence rate of total SD (patients with at least one form of SD) found in this study $(48.7 \%)$ is similar to the rates found in some previous studies.8,9 The rates of the specific SDs are also within the range reported by Oyekanmi and his colleagues. ${ }^{11}$ Also similar to the reports of some previous authors, erectile dysfunction was the commonest type of specific sexual dysfunction. ${ }^{11}$ However, some researchers have found rates that were higher ${ }^{13,18}$ than those found in this study. Variation in reported rates of SD reflects differences in study population, method of enquiry and types of dysfunction being assessed.

The prevalence rates of total and all the specific SD were significantly higher in the patient group than in the control group. This finding is in keeping with previous report that SD is more prevalent among mentally ill patients and patients taking psychotropic medications than among healthy controls.8.9

The relatively higher prevalence of SDs (total and specific) found in this study portends important implications for clinical practice; clinical experience suggests that SD among psychiatric patients has been underestimated; clinicians often do not enquire about sexual problems, worse still, most patients do not spontaneously report their sexual difficulties. In this study, less than one- third $(21.1 \%)$ of the patients with SD never discussed their sexual problems with their doctors. Consequently, patients suffer the distressing effect of SD in silence with its attendant negative effect on compliance with medications. Awareness of the prevalence of SD in psychiatric patients would enhance alertness on the part of the clinicians and improve their attitude towards sexual difficulties in the patients.

\section{Premorbid sexual functioning}

An evaluation of sexual dysfunction in psychiatric patients should take into consideration premorbid sexual functioning. In this study, $38.3 \%$ of the patients had at least one form of SD, but only $18.7 \%$ admitted having SD prior to the onset of the illness. Thus, it is plausible to assume that the mental illness or the adverse effect of their psychotropic medications, or both, contributed substantially to the excess proportion of subjects with SD. However, this study could not differentiate the effect of mental illness from that of the psychotropic medications. It is advocated that future studies address this concern.

\section{Correlates of SD}

This study found a significant association between differ- ent types of SD and, age, marital status, class of psychotropic medication, dose of anti-psychotics, duration of illness and treatment, poor compliance with medication and low self-esteem:

\section{Age and SD}

Age was found to be associated with only erectile dysfunction; although age did not independently predict SD, the risk of developing SD increased with age (odds $=0.980)$ and age was significantly inversely correlated with sexual performance (IIEF global scores). Previous authors also reported an association between age and SD especially erectile dysfunction. ${ }^{11}$

The decrease in hormonal influence and, perhaps, the decline in sexual zest that generally come with ageing may be responsible for these findings.

\section{Marital status and SD}

Similar to the findings of this study a significant relationship between marital status and SD have been reported by some authors. ${ }^{11}$ In this study, the married men were five times more likely to report SD (especially intercourse and overall dissatisfaction) than the single. Married men are more likely to be aware of, and sensitive to an existing sexual difficulty. Besides the desire to satisfy their spouse sexually, SD may heighten anxiety and further impair sexual performance. Thus SD could be more worrisome to the married men and more likely to be reported by them.

\section{Antipsychotic medication and SD}

This study did not assess the effect of specific psychotropic medications on SD because larger numbers of patients would be required for that purpose rather the effect of classes of psychotropic medications was assessed. Significantly higher proportion of patients on typical antipsychotics than those on atypical and other psychotropic drugs reported SD, similar to previous research findings ${ }^{4,30}$. The dichotomy of sexual side effects especially between the typical and atypical anti-psychotics may be related to the different effects of antipsychotics on dopaminergic signaling, with the typical anti-psychotics having more direct dopamine (D2) receptor antagonism and significantly increasing circulating prolactin levels while the atypical group has less of an effect on increasing prolactin. Therefore the atypical anti-psychotics seem to carry expectations for fewer sexual side effects, an important advantage that physicians, especially in Nigeria and other developing African countries should utilize to minimize SD. 


\section{Dose of anti-psychotic medication and SD}

The mean dose of anti-psychotic medications (chlorpromazine equivalents) was significantly higher among patients with SD than those without it, and dose of anti-psychotics independently predicted global SD. Similar findings were reported by previous authors. ${ }^{8}$ These findings highlight the need for physicians to avoid excessive dosing and maintain their patients on the minimum effective dose of anti-psychotics so as to minimize the risk of SD.

\section{Poly-pharmacy and SD}

The use of more than one psychotropic medication in treating a patient was significantly associated with erectile dysfunction. Unfortunately, mono-therapy is rarely used in current psychiatric practice especially in Nigeria. The reason for this is multifactorial, including perceived insufficient or delayed response to a single psychotropic medication, presence of co- morbidity, unremitting symptoms or refractory illness episode, and the need to prescribe a long acting anti-psychotic in addition to oral medication on account of poor medication compliance. In this study, more than one-third of the patients were being treated with two or more psychotropic medications. The combined effects of the drugs may increase the risk of SD. Similar findings were reported by Harrington and his colleagues. ${ }^{30,31}$ Restricting pharmacotherapy to only absolutely necessary drugs, and for the necessary duration of treatment, may reduce the rate of treatment emergent SD.

\section{SD and compliance with medications}

More than one-third (37.3\%) of the patients reported poor compliance with their psychotropic medications and majority of them $(57.1 \%)$ cited perceived sexual side effects as the reason for non-adherence. Similarly, Ronsenberg and his colleagues ${ }^{18}$ found that the presence of side effect affected compliance, and $41.7 \%$ of affected men admitted that they stopped their medications at some point during treatment due to experience of side effects. SD is distressing and patients are often more concerned with the sexual side effects of their medication than any other side effect. ${ }^{21}$ In this study, the high rate of reported poor compliance, perhaps, reflects the sexual concern of a population who are predominantly in their sexually active age group. These findings underscore the imperative of measures that will reduce the incidence of treatment-emergent SD and ensure prompt and adequate treatment offfected patients.

\section{SD and self esteem}

Low self-esteem was significantly associated with SD in this study. It is worthy of note though, that low self-esteem could be a consequence of mental illness even in patients who do not experience SD. However, untreated SD has been found to further lower the self-esteem of the patients..$^{20,21}$ The findings of this study are in keeping with that knowledge, as the mean self-esteem score was significantly lower in patients with SD than those without SD. Future studies that will further elucidate the relationship between self-esteem, mental illness and SD, perhaps, by assessing the differential contribution of mental illness, and SD to the variance in low self-esteem is advocated. In particular, low self- esteem was significantly associated with erectile dysfunction and overall dissatisfaction. The relationship between SD and low self-esteem is, perhaps, not surprising considering the socio-cultural relevance of adequate sexual functioning. A man's lack of capacity to satisfy his wife sexually diminishes his sense of masculinity and self-worth, and may be associated with self-stigma leading, invariably, to low self-esteem. Thus, effective treatment to bring about significant improvement in confidence and self-esteem is an important component of management.

\section{Inter relationship of sexual function domains}

In this study, erectile function of the IIEF had strong positive relationship with overall satisfaction domain. This finding reinforces the important role of good penile erection in sexual activity. Men associate penile erection with their identity, masculinity and feeling of self-worth and satisfaction but poor erection hinders or interferes with the subjective feeling of enjoyment at other stages of sexual intercourse. Furthermore, erectile dysfunction was the commonest type of SD in our sample, a finding similar to previous reports. ${ }^{21,31}$ This underscores the need for proactive interventions in male psychiatric patients with SD especially ED so as to enhance their sexual satisfaction and quality of life.

\section{Conclusion}

Rates of total and specific SD were high, and significantly higher among the patients than healthy control. Substantially, SD was underreported to the treating physicians and a significant relationship was found between SD and, being married, use of high dose of antipsychotic drugs, use of typical antipsychotics, poly-pharmacy, duration of illness and treatment, poor compliance to medication and low self-esteem. 
Physicians should be aware that SD is prevalent among their patients, take sexual history as part of their routine clinical assessment, treat SD promptly and maintain their patients on the minimum effective dose of psychotropic drugs in order to prevent poor compliance with medication, improve self-esteem and enhance overall treatment success.It is important to note that, beyond biomedical intervention, the role of psychotherapeutic interventions in the management of SD cannot be ignored. Sex therapy techniques, behavioural and cognitive as well as psychodynamic and educational interventions, in group- and in couple-setting, have been found to offer some relieving effects on sexual dysfunction ${ }^{32}$.

\section{Limitations of the study}

The results of this study, although interesting and strengthened by the presence of a control group, are limited due to a relatively small sample size and the inherent challenges associated with hospital based studies. Besides, the study was cross sectional in design, thus it was not possible to separate the effects of the mental illness from those of the psychotropic medication.

\section{Acknowledgement}

The authors thank the participants for their cooperation and patience in the course of data collection.

\section{Conflict of interest}

The authors declare no conflict of interest.

Research was self-sponsored.

\section{Source of support:}

None

Authors' contributions: Both authors contributed extensively to the work presented in this paper. The first author, S.O. Osasona conceived and designed the study, performed statistical analysis and contributed to manuscript writing. The second author, M. Ehimigbai contributed substantially to data collection, manuscript writing and provided valuable comments to the paper in general. Both authors read and approved the final manuscript.

\section{References}

1. Laumann EO, Park A, Rosen RC. Sexual dysfunction in the United States: Prevalence and predictors $J A M A$ 1999;281:537-44.ncbi.nlm.nih.gov/pubmed/19512977

2. Rosen RC, Bachmann GA. Sexual well-being, happiness, and satisfaction, in women: the case for a new conceptual paradigm. I Sex Marital Ther. 2008;34(4):291-7 DOI: 10.I080/00926230802096234

3. World Health Organization: International Classification of Diseases, $10^{\text {th }}$ Revision (ICD-10) Geneva: WHO;1992.

4. Kandrakonda S, Jally MR, Kesava Reddy SR, Miryala G. Prevalence of sexual dysfunction in patients with mental illness receiving psychotropic medication. AP J Psychol Med 2014;15(2):235-9. medInd.nic.in/aag/ t14/i2/aagt14i2p235.pdf

5. Moreira ED, Glasser DB, Nicolosia, Duarte FG, Gingell C. GASSAB Investigators' Group Sexual problems and help-seeking behavior in adults in the United Kingdom and Continental Europe. BJU Int 2008;101:1005-11.PMID18261155

6. Fajewonyomi BA, Orji SO, Adeyemo AO. Sexual Dysfunction among Female Patients of Reproductive Age in a Hospital Setting in Nigeria. J Health Popul Nutr 2007;25(1):101-6. PMCID:PMC3013270

7. Nwagha UI, Oguanuo TC, Ekwuazi K, Olubosokun IO, Nwagha TU, Onyebuchi AK et al. Prevalence of sexual dysfunction among females in a University Community in Enugu, Nigeria. Niger J Clin Pract 2014;17(6):791-6. DOI: 10.4103/1119-3077.144401

8. Smith SM, O'Keane V and Murray R. Sexual Dysfunction in patients taking conventional antipsychotics medication. Br J Psychiatry 2002; 181(1): 49-55. DOI: 10.1192/bjp.181.1.49

9. Oju GO, Udofia O, Kuteyi OB. Sexual dysfunctions among psychiatric out-patients in Calabar. Niger J Psychiatry 2009;7(2)n.p http://dx.doi.org/10.4314/njpsyc.v7i2.50113

10. Aizenberg D, Zemishlany Z, Dorfman-Etrog P, Weizman A. Sexual dysfunction in male schizophrenic patients. J Clin Psychiatry 1995;56:137-41. Pubmed/7713851 11. Oyekanmi AK, Adelufosi AO, Abayomi O, Adebowale TO. Demographic and clinical correlates of sexual dysfunction among Nigerian out-patients on conventional antipsychotic medications. BMC Res Notes 2012;5:267. DOI: 10.1186/1756-0500-5-267

12. Letourneau EJ, Schewe PA, Fruch BC: Preliminary evaluation of sexual problems in Combat relevance with PTSD. J Trauma Stress 1997;10:125-32. DOI: 10.1023/A:1024868632543

13. Kesava Reddy SR and Miryala G. Prevalence of sexual dysfunction in patients with mental illness receiving psychotropic medication APJ Psychol Med 2014;15(2):23539. DOI: $10.3410 /$ f:12104957.13253056 
14. Serretti A, Chiesa A. A meta-analysis of sexual dysfunction in psychiatric patients taking antipsychotic. Int Clin Psychopharmacol 2011;26(3):130-40. DOI: 10.1097/ Y1C.00013e328341e434

15. Kockott G, Pfeiffer W. Sexual disorders in non acute psychiatric patients. Compr Psychiatry 1996;37:56-61 DOI: 10.1016/50010-440X(96)90052-8

16. Waldinger MD. Psychiatric disorder and sexual dysfunction. Handb Clinical Neurol 2015;130:469 - 89. DOI: 10.16/B978-0-444-63247.00027-4

17. Bella AJ and Shamloul R. Psychotropic and sexual dysfunction. Cent European J Urol 2013;66(4):466-71. DOI: $10.5173 /$ ceju.2013.04.art22

18. Rosenberg KP, Bleiberg KL, Koscis J, Gross C. A survey of sexual side effects among severely mentally ill patients taking psychotropic medications: Impact on compliance. J sex Marital Ther 2003;29(4):289-96. Ncbi. nlm.nih.gov/pubmed/14504017

19. Clayton A, pradiko JF, Croft HA, Montano CB, Leadbetter RA, Bolden-Watson $C$ et al. Prevalence of Sexual Dysfunction Among Newer Antidepressants. J Clin Psychiatry 2002;63(4):357-66. PMID/12000211

20. Malik P. Sexual dysfunction in Schizophrenia. Curr Opin Psychiatry 2007;20:138-42. DOI: 1097/YCO$06013 \mathrm{e} 328017 \mathrm{f} 6 \mathrm{c} 4$

21. Althof SE, O'Leary MP, Cappelleri JC, Crowlex AR, Tseng LJ, Collins S. Impact of erectile dysfunction on confidence, self-esteem and relationship satisfaction after 9 months of sildenafil citrate treatment. $J$ Urol 2006; 176(5):2132-7. DOI: 10.1016/j.juro.2006.07. 019Pubmed/17070276

22. Modebe $O$. Erectile failure among medical clinic patients. Afr J Med Science 1990;19:259-64. Pubmed/2127.993

23. Okulate G, Oladokun O, Dogunro AS. Erectile dysfunction: prevalence and relationship with depression, alcohol abuse and panic disorder. Gen Hosp
Psychiatry 2003;25(3):209-13. DOI: 10.1016/S01638343(03)0015-X

24. Mosaku KS, Ukpong DI. Erectile dysfunction in a sample of patients attending a psychiatric out-patient department. Int J Impotence Res 2009;21:235-39.DOI: 10.1038/ijir.2009.16

25. Araoye OM. Research methodology with statistics for health and social sciences. 2nd edition, Nathadex publishers;; 2004; 117-120

26. Rosen RC Riley A, Wagner G. The International Index of erectile function (IIEF): a multidimensional scale for assessment of erectile dysfunction. Urology 1997;49(6):822-30. DOI: 1016/S0090-4295(97)00238-O

27. Olisah V.O., Sheikh TL, Abah ER, Mamud, Ajeigbe AT. Sociodemographic and clinical correlates of sexual dysfunction among psychiatric out-patient receiving common psychotropic medication in a Neuropsychiatric Hospital in Northern Nigeria. Niger J Clin Pract. 2016; 19:799-806. DOI: 10.4103/1119-3077.180063

28. Rosenberg M. Society and the adolescent Self-Image. Princeton, NJ: Princeton University Press, 1965

29. Okwaraji FE, Aguwa EN, Shiweobi C. Life Satisfaction, Self-esteem and Depression in a sample of Nigerian Adolescents. Int Neuropsychiatr Dis J 2015;5(3):1-8. DOI: 10.9734/INDJ/2016/20805

30. Khawaja MY. Sexual dysfunction in male patients taking antipsychotics. J Ayub Med Coll 2005;17(3):73-75

31. Hiroto I, Asuka K, Teruhiko H. Poly-pharmacy and excessive dosing: psychiatrists' perceptions of antipsychotic drug prescription. Br J Psychiatry 2005;187:2437. DOI: 10.1192/bjp.187:3.243

32. Assalian Pierre. Psychological and interpersonal dimensions of sexual function and dysfunction. Arab Journal of Urology 2013; 11 (3): 217-221. 10.1016/j. aju.2013.07.007 